\title{
Analysis of Prediagnostic Circulating Levels of Gonadotropins and Androgens with Risk of Epithelial Ovarian Cancer
}

\author{
Deepak Parchwani $^{1}$ Sagar Jayantilal Dholariya ${ }^{10}$ \\ Vivek Kumar Sharma ${ }^{3}$ Alpana Saxena ${ }^{4}$ Digishaben D. \\ ${ }^{1}$ Department of Biochemistry, All India Institutes of Medical Sciences, \\ Rajkot, Gujarat, India \\ 2 Department of Biochemistry, Geetanjali Medical College, Udaipur, \\ Rajasthan, India \\ ${ }^{3}$ Department of Physiology, All India Institutes of Medical Sciences, \\ Rajkot, Gujarat, India \\ ${ }^{4}$ Department of Biochemistry, Hamdard Institute of Medical Sciences \\ and Research, New Delhi, India
}

Sohil Takodara ${ }^{2}$ Ragini Singh ${ }^{1}$

\author{
Address for correspondence Sagar Jayantilal Dholariya, MD, \\ Department of Biochemistry, All India Institutes of Medical Sciences, \\ Rajkot, 360001, Gujarat, India \\ (e-mail: drsagar.dholariya@gmail.com). \\ ${ }^{5}$ Department of Radiology, Pandit Dindayal Upadhyay Medical \\ College, Rajkot, Gujarat, India
}

J Lab Physicians 2022;14:47-56.

\begin{abstract}
Keywords

- epithelial ovarian cancer

- follicle-stimulating hormone

- dehydroepiandrosterone-sulfate

Background Prevailing experimental and epidemiological evidence supports the role of circulating endogenous sex steroid hormones in the pathogenesis of ovarian carcinogenesis by dysregulation of cell differentiation, proliferation, and apoptosis but is scarce and inconclusive.

Objectives This article evaluates the role of circulating levels of gonadotropins (follicle-stimulating hormone [FSH], luteinizing hormone [LH]) and androgens (testosterone, dehydroepiandrosterone-sulfate [DHEA-S]) for the risk of epithelial ovarian cancer in a case-control approach using samples collected in advance of clinical diagnosis.

Materials and Methods A total of 100 epithelial ovarian cancer (EOC) patients and 100 healthy female controls were consequently enrolled in this hospital-based casecontrol study. Serum FSH, LH, testosterone, and DHEA-S were measured based on the principle of electrochemiluminescence immunoassay. Suitable descriptive statistics were used for different variables.

Results Median values of FSH (58.9 vs. $45.5 \mathrm{IU} / \mathrm{L}, p=0.02$ ) and DHEA-S (163.43 vs. $142.2 \mathrm{ug} / \mathrm{dL}, p=0.03$ ) were significantly high in EOC patients compared with controls. Conditional logistic regression was used to estimate the odds ratio (OR) across increasing thirds of FSH and DHEA-S concentrations, and the results revealed that the highest third tertile of FSH $(>72.6 \mathrm{IU} / \mathrm{L} ; \mathrm{OR}=3.0$, confidence interval $[\mathrm{CI}]=1.24$ 7.29, $p$ trend $=0.04$ ) and DHEA-S ( $>194.2 \mathrm{ug} / \mathrm{dL} ; \mathrm{OR}=3.8, \mathrm{Cl}=1.26-11.61, p$ trend $=0.03$ ) were significantly associated with increased risk of ovarian cancer in
\end{abstract}

published online January 18, 2022
DOI https://doi.org/ 10.1055/s-0041-1741443. ISSN $0974-2727$.
(C) 2022. The Indian Association of Laboratory Physicians. All rights reserved.

This is an open access article published by Thieme under the terms of the Creative Commons Attribution-NonDerivative-NonCommercial-License, permitting copying and reproduction so long as the original work is given appropriate credit. Contents may not be used for commercial purposes, or adapted, remixed, transformed or built upon. (https://creativecommons.org/ licenses/by-nc-nd/4.0/)

Thieme Medical and Scientific Publishers Pvt. Ltd., A-12, 2nd Floor, Sector 2, Noida-201301 UP, India 
postmenopausal and premenopausal women, respectively. The statistically significant trend observed for FSH in postmenopausal women, remained only for the subgroup with menopause duration greater than 10 years $(\mathrm{OR}=5.9, \mathrm{Cl}=1.33-26.66, p$ trend $=0.04)$. FSH and DHEA-S concentrations and ovarian cancer risk were internally consistent with groups defined by oral contraceptive pill use, hormone replacement therapy, and smoking. However, no evidence was found for the association between serum $\mathrm{LH}$ and testosterone level with the occurrence of ovarian tumorigenesis.

Conclusion Prediagnostic circulating concentration of FSH and DHEA-S unveiled a significant positive association with augmented risk of EOC, thus might serve as a predictive marker for the susceptibility to ovarian carcinogenesis and should be added in the screening profile of EOC for early recognition and scheduling necessary interventions/management strategies.

\section{Introduction}

Ovarian cancer is the leading cause of death from gynecological neoplasms and is considered the second most common malignancy of the female reproductive system. ${ }^{1}$ In India, epithelial ovarian cancer (EOC) alone is responsible for $5.9 \%$ of all cancers, being more prevalent in the age group of 35 to 45 years. $^{2,3}$ Regardless of attainment in its surgical and systemic handling, the 5 -year survival rate remains low. ${ }^{1}$ This is a source of concern for the Indian health care system; adequate management is required to optimize patient care. First, however, it is essential to identify the early markers involved in the pathophysiological process of EOC to prevent complications and to initiate early management.

The low survival rate of ovarian malignancies can be attributed to many factors, including the absence of suitable screening tests, nonspecific symptoms, and long symptomless periods, and the biological mechanisms accountable for its development/progression are not clear. Although heritability accounts for 5 to $10 \%$ of all cases, ${ }^{4}$ but by and large, the etiology of ovarian carcinogenesis is not conclusive enough. Based on the animal experiments, ${ }^{5,6}$ cell culture studies, ${ }^{7}$ and epidemiological observations, it is hypothesized that endogenous hormones of adrenal and ovarian origin play a significant role in ovarian tumorigenesis through controlling cellular proliferation, differentiation, and apoptotic rates. ${ }^{8,9}$

Incessant ovulation hypothesis and gonadotropin hypothesis have been proposed for the pathogenesis of ovarian cancer, with former postulating that the risk of EOC surges with the numeral of ovulatory cycles because of amplified contact of the disturbed epithelium of the ruptured follicles to mitotic stimuli and recurrent repair..$^{10,11}$ In humans, epidemiologic evidence in support of the ovulation hypothesis are the observations that multiple pregnancies, breastfeeding, hormone replacement therapy (HRT), and the use of oral contraceptives pills (OCPs) seem to have a protective effect by decreasing the synthesis and secretion of folliclestimulating hormone (FSH) and luteinizing hormone (LH) through gonadotropin-releasing hormone (GnRH) signals. ${ }^{12}$ The gonadotropin hypothesis proposes that increased serum levels of androgens (predominantly dehydroepiandroster- one) induced by elevated gonadotropins stimulate increased proliferation and malignant alteration of the ovarian epithelium entombed within inclusion cysts. The observations substantiate that ovarian carcinogenesis is more frequent in women suffering from a polycystic ovarian syndrome where LH levels are constantly increasing. ${ }^{13}$ In vitro and in vivo studies have also suggested that circulating testosterone levels can directly increase ovarian cancer cell proliferation through androgen receptor signaling, ${ }^{6}$ and other androgenslike dehydroepiandrosterone-sulfates (DHEA-S) indirectly affect risk via conversion to testosterone. ${ }^{14}$

In divergence, few studies ${ }^{15,16}$ did not support the original proposition and reported an inverse association between androgens of adrenal and ovarian origin with ovarian cancer. Additionally, reducing elevated serum gonadotropins by GnRH agonists, antiandrogens, or antiestrogens in ovarian cancer patients did not prevent recurrence or lead to growth restriction. ${ }^{17-19}$ All these findings advocate that reproductive history influences the risk of ovarian cancer, that is, endogenous hormones have an etiologic role in ovarian cancer. Moreover, endogenous hormone levels cannot be changed easily, unlike exogenous factors. Thus, it becomes much more necessary to detect its association with ovarian carcinogenesis. However, there is a paucity of information about concentrations of endogenous hormones in the occurrence of EOC, specifically in the Indian population. Thus, in the present study, an attempt has been made to investigate the role of prediagnostic circulating concentrations of FSH, $\mathrm{LH}$, and androgens (e.g., testosterone, DHEA-S) with the risk of EOC using a case-control approach.

\section{Materials and Methods}

\section{Ethical Consideration}

The study was conducted under the ethical guidelines of the Declaration of Helsinki (1964) and its later amendments on biomedical research on humans and was approved by the Institutional Human Research Ethical Committee. Informed consent was obtained from each participant following a study protocol after providing a detailed study overview. 


\section{Participants and Study Protocol}

This case-control study was conducted in the Department of Biochemistry and Obstetrics and Gynecology of Maulana Azad Medical College and associated Lok Nayak Hospital, Delhi, India. The participants recruited for the present study were based on a consecutive sampling technique. That is, all the participants who fulfilled the inclusion and exclusion criteria were included, ensuring that 1:1 matching was done. The study included a total of 200 participants (100 newly diagnosed EOC patients and 100 healthy controls).

\section{Participant Selection}

Patients presenting with plausible symptoms of ovarian cancers reminiscent of pelvic pain, abdominal swelling, bloating, emesis, anorexia, bleeding after sexual intercourse, irregular menstruation, and pain were considered apparent case participants. ${ }^{20}$ Prediagnostic venous sampling was done from all these plausible patients. After histopathological confirmation for EOC, the patients were finally enrolled for the study. Thus, patients with newly diagnosed, histopathologically confirmed EOC were included in this study. Patients with cancers other than EOC, metastasized cancers from other organs, and benign ovarian lesions were excluded. Other criteria for exclusion were patients with any severe illness, impairment of speech, hearing, vision, or cognition, or any significant medical illnesses that prevented participants from adhering to the protocol, lack of approval by a physician, and patients showing disinterest or refusal to sign the consent form.

Healthy controls were selected randomly from the outpatient department who visited the hospital for routine health check-ups and were not suffering from any acute or chronic disease nor taking any drugs believed to affect the physiological processes.

Participants with regular menstrual periods and had undergone hysterectomy with at least one ovary preserved were included in the premenopausal group. Participants with cessation of the menstrual period since 1 year along with FSH level greater than $40.0 \mathrm{IU} / \mathrm{L}$ (physiological menopause) and undergone hysterectomy with bilateral oophorectomy were included in the menopausal group. ${ }^{21}$

\section{Participants' Examination and Measurements}

A detailed present and past history of each participant were recorded, including name, address, occupation, economic status, age, age at menarche, age at full-term pregnancy, age at menopause, parity, phase of menstrual cycle at the time of blood collection, menopausal status, duration of menopause, use of OCP, use of HRT, nutritional and personal habits, education, medication, and history suggestive of any systemic illness. Age was defined as the age at the time of the interview (though no documentary proof had been entertained).

\section{Sample Collection and Analysis}

Venous sampling was done from all participants for biochemical determinations; however, samples of only histopathologically confirmed EOC cases and healthy controls were selected for further biochemical analysis. FSH, LH, testosterone, and DHEA-S were measured on Roche-Elecsys 2010 (Germany) analyzer based on the principle of electrochemiluminescence immunoassay. Each pair of cases and controls was analyzed on the same batch and the same day after quality control evaluation to prevent any random and systemic error in reporting value.

\section{Statistical Analysis}

The statistical analyses were performed using a Med Cal statistical software and Statistical Package for Social Sciences for Windows version 17.0 (SPSS Inc, Chicago, Illinois, United States). Data were expressed as mean \pm standard deviation (continuous variables) or as percentages of total (categorical variables). Two-group comparisons were made using chisquare for categorical variables and Student's $t$-tests for continuous variables. Mann-Whitney $U$ test and KruskalWallis test were used to compare the median. The odds ratio (OR) was calculated by conditional logistic regression to detect the risk of EOC occurrence. For all analyses, two-sided probability values less than 0.05 were considered statistically significant.

\section{Results}

The mean acceptance rate of the study protocol was $68.25 \%$ $(n=200)$ by eligible participants $(n=293$; EOC patients, $n=141$; healthy participants, $n=152$ ) and there was no difference between patients versus control group in the number of participants who refused to participate in the study or withdrew after the initial consent $(p=0.07$; EOC patients, $n=41$; healthy controls, $n=52$ ).

- Table 1 depicts the subgroup statistics and analysis of data for clinical characteristics of the study participants. Healthy controls had an average age of $51.0 \pm 10.04$ years, while EOC patients had an average age of $52.8 \pm 11.82$ years, and there were no significant difference in age $(p=0.24)$, age at menarche ( $p=0.37)$, age at full-term pregnancy ( $p=0.67)$, age at menopause $(p=0.31)$, parity $(p=0.98)$, phase of menstrual cycle at the time of blood collection $(p=0.92)$, menopausal status $(p=0.77)$, duration of menopause $(p=0.96)$, OCP use $(p=0.28)$, HRT use $(p=0.86)$, and smoking $(p=0.82)$ between ovarian cancer patients and controls. After hospital admission, the mean duration of EOC confirmation and venous sampling for hormone assay was 12 days \pm 4 days and 16 hours \pm 6 hours, respectively.

Among the inducted ovarian cancer cohort, mucinous histopathological type of malignancy was most common, observed in $44 \%$ ( $n=44$ ) of patients; 40 patients $(40 \%)$ had a serous type, tailed by endometrioid ( $8 \%$ ), clear cell ( $8 \%$ ), and anaplastic (4\%) histopathological type. The majority of the cases $(66 \%)$ were moderately differentiated (grade 2 ), followed (20\%) by poorly differentiated (grade 3 ) and welldifferentiated, grade 1 (14\%). In addition, 76 patients $(76 \%)$ were in advanced as per the International Federation of Gynecology and Obstetrics (FIGO) staging, and 24\% were in early FIGO staging. All cases and controls were matched according to infertility, tubal ligation, and hysterectomy 
50 Prediagnostic Circulating Levels of Gonadotropins and Androgens with Risk of EOC Parchwani et al.

Table 1 Baseline characteristics features of study participants

\begin{tabular}{|c|c|c|c|}
\hline Features & Ovarian cancer cases $(N=100)$ & Controls $(N=100)$ & $p$-Value \\
\hline Overall age (mean $\pm S D$, in years) & $52.8 \pm 11.82$ & $51.0 \pm 10.04$ & $0.24^{\mathrm{a}}$ \\
\hline Age at menarche (mean $\pm S D$, in years) & $13.5 \pm 1.9$ & $13.3 \pm 1.2$ & $0.37^{\mathrm{a}}$ \\
\hline Age at full term pregnancy (mean $\pm S D$, in years) & $25.5 \pm 5.3$ & $25.2 \pm 4.9$ & $0.67^{\mathrm{a}}$ \\
\hline Age at menopause (mean $\pm S D$, in years) & $49.5 \pm 4.6$ & $48.9 \pm 3.7$ & $0.31^{\mathrm{a}}$ \\
\hline \multicolumn{4}{|l|}{ Parity, $n(\%)$} \\
\hline 0 & $28(28.0)$ & $27(27.0)$ & $0.98^{\mathrm{b}}$ \\
\hline $1-2$ & $44(44.0)$ & $45(45.0)$ & \\
\hline$>2$ & $28(28.0)$ & $28(28.0)$ & \\
\hline \multicolumn{4}{|l|}{ Menstrual cycle day, $n(\%)$} \\
\hline Follicular phase $(0-12 \mathrm{~d})$ & $16(38.1)$ & $15(34.1)$ & $0.92^{b}$ \\
\hline Ovulation phase (13-16 d) & $10(23.8)$ & $10(22.7)$ & \\
\hline Luteal phase (17-34 d) & $16(38.1)$ & $19(43.2)$ & \\
\hline \multicolumn{4}{|l|}{ Menopause status, $n(\%)$} \\
\hline Premenopausal & $42(42.0)$ & $44(44.0)$ & $0.77^{b}$ \\
\hline Postmenopausal & $58(58.0)$ & $56(56.0)$ & \\
\hline \multicolumn{4}{|l|}{ Duration of menopause, $n(\%)$} \\
\hline$<5 \mathrm{y}$ & $14(24.1)$ & $13(23.2)$ & $0.96^{\mathrm{b}}$ \\
\hline $5-10 y$ & $20(34.5)$ & $21(37.5)$ & \\
\hline$>10 y$ & $24(41.4)$ & $22(39.3)$ & \\
\hline \multicolumn{4}{|l|}{ OCP use, $n(\%)$} \\
\hline Yes & $20(20.0)$ & $28(28.0)$ & $0.28^{\mathrm{b}}$ \\
\hline Never & $80(80.0)$ & $72(72.0)$ & \\
\hline \multicolumn{4}{|l|}{ HRT use, $n(\%)$} \\
\hline Yes & $24(24.0)$ & $23(23.0)$ & $0.86^{\mathrm{b}}$ \\
\hline Never & $76(76.0)$ & $77(77.0)$ & \\
\hline \multicolumn{4}{|l|}{ Smoking } \\
\hline Yes & $11(11.0)$ & $12(12.0)$ & $0.82^{b}$ \\
\hline Never & $89(89.0)$ & $88(88.0)$ & \\
\hline \multicolumn{4}{|l|}{ Histopathology, $n$ (\%) } \\
\hline Mucinous & $44(44.0)$ & - & - \\
\hline Serous & $40(40.0)$ & - & - \\
\hline Endometrioid & $8(8.0)$ & - & - \\
\hline Clear cell & $4(4.0)$ & - & - \\
\hline Anaplastic & $4(4.0)$ & - & - \\
\hline \multicolumn{4}{|l|}{ Grade } \\
\hline Well differentiated - Grade 1 & $14(14)$ & - & - \\
\hline Moderately differentiated - Grade 2 & $66(66)$ & - & - \\
\hline Poorly differentiated - Grade 3 & $20(20)$ & - & - \\
\hline \multicolumn{4}{|l|}{ FIGO staging } \\
\hline Early (Stage I and II) & $24(24.0)$ & - & - \\
\hline Advanced (Stage III and IV) & $76(76.0)$ & - & - \\
\hline
\end{tabular}

Abbreviations: FIGO, International Federation of Gynecology and Obstetrics; HRT, hormone replacement therapy; OCP, oral contraceptive pill; SD, standard deviation.

${ }^{a} p$-Values are calculated by Student's $t$-test.

${ }^{b} p$-Values are calculated by Chi-square test. 
Table 2 Serum level of FSH, LH, testosterone, and DHEA-S in study participants

\begin{tabular}{|l|l|l|l|}
\hline Hormones in median and range & Ovarian cancer cases $(N=100)$ & Controls $(N=100)$ & $p$-Value \\
\hline FSH $(\mathrm{IU} / \mathrm{L})$ & $58.9(8.3-106.7)$ & $45.5(6.6-101.2)$ & 0.02 \\
\hline LH (IU/L) & $48.7(4.3-98.2)$ & $47.7(2.9-81.3)$ & 0.67 \\
\hline Testosterone $(\mathrm{ng} / \mathrm{mL})$ & $0.42(0.12-0.80)$ & $0.39(0.09-0.78)$ & 0.75 \\
\hline DHEA-S $(\mathrm{ug} / \mathrm{dL})$ & $163.43(99.4-258.9)$ & $142.2(96.5-245.4)$ & 0.03 \\
\hline
\end{tabular}

Abbreviations: DHEA-S, dehydroepiandrosterone-sulfate; FSH, follicle-stimulating hormone; LH, luteinizing hormone.

${ }^{a} p$-Values are calculated by Mann-Whitney $U$ test.

(data not shown). Thus, there was no significant difference in baseline characteristics and clinical variables among cases and controls, indicating that the EOC and control groups were well matched.

- Table 2 represents group statistics and data analysis for serum levels of FSH, LH, testosterone, and DHEA-S in ovarian cases and control individuals. The median values of serum $\mathrm{LH}$ were 47.7 and $48.7 \mathrm{IU} / \mathrm{L}$ in control and patients, respectively. The corresponding values for testosterone were 0.39 and $0.42 \mathrm{ng} / \mathrm{mL}$, respectively. Median estimated serum FSH and serum DHEA-S levels in healthy controls were $45.5 \mathrm{IU} / \mathrm{L}$ and $142.2 \mathrm{ug} / \mathrm{dL}$, respectively. Equivalent values in EOC patients were $58.9 \mathrm{IU} / \mathrm{L}$ and $163.43 \mathrm{ug} / \mathrm{dL}$, respectively, that is, the increase in serum FSH $(p=0.02)$ and DHEA-S $(p=0.03)$ levels in patients were statistically significant.

The relationship between FSH tertiles and various variables has been shown in - Table 3 to have a stratified analysis for the association with EOC; serum FSH levels are expressed as low $(<32.5 \mathrm{IU} / \mathrm{L})$, mid $(32.5-72.6 \mathrm{IU} / \mathrm{L})$, and high $(>72.6 \mathrm{IU} / \mathrm{L})$ tertiles. High tertile FSH level was found to be significantly associated with increased risk of ovarian cancer compared with low and mid tertile level, in women with parity of 0 to $2(\mathrm{OR}=2.7$, confidence interval $[\mathrm{CI}]=1.17-6.30 ; p$ trend $=0.03)$ and in postmenopausal women $(\mathrm{OR}=3.0, \mathrm{CI}=1.24-7.29, p$ trend $=0.04)$. However, the statistically significant trend observed in postmenopausal women remained only for the subgroup with menopause duration of greater than 10 years $(\mathrm{OR}=5.9$, $\mathrm{CI}=1.33-26.66, p$ trend $=0.04$ ). High tertile FSH level was also found to be significantly allied with increased risk of ovarian cancer in subgroups who never used to smoke $(\mathrm{OR}=3.7, \mathrm{CI}=1.7-8.18, p$ trend $=0.02)$, never used OCP $(\mathrm{OR}=2.5, \mathrm{CI}=1.17-5.51, p$ trend $=0.04)$, and never used HRT $(\mathrm{OR}=3.1, \mathrm{CI}=1.39-7.15, p$ trend $=0.01)$.

The relationship between DHEA-S tertiles and various variables has been shown in - Table 4 to have a stratified analysis for the association with EOC, and serum DHEA-S levels are expressed as low $(<106.9 \mathrm{ug} / \mathrm{dL})$, mid (106.9$194.26 \mathrm{ug} / \mathrm{dL}$ ), and high tertile ( $>194.2 \mathrm{ug} / \mathrm{dL}$ ). High tertile DHEA-S level was found to be significantly associated with increased risk of ovarian cancer compared with low and mid tertile level, in women with parity of 0 to $2(\mathrm{OR}=2.9$, $\mathrm{CI}=1.23-7.13$; $p$ trend $=0.02$ ) and in premenopausal women $(\mathrm{OR}=3.8, \mathrm{CI}=1.26-11.61, p$ trend $=0.03)$. High tertile DHEA-S was also found to be significantly associated with increased risk of ovarian cancer in subgroups who never used to smoke $(\mathrm{OR}=2.7, \mathrm{CI}=1.33-5.67, p$ trend $=0.01$ ), never used OCP $(\mathrm{OR}=3.1, \mathrm{CI}=1.35-7.15, p$ trend $=0.01)$, and never used HRT $(\mathrm{OR}=2.5, \mathrm{CI}=1.10-5.33, p$ trend $=0.02)$.

-Table 5 represents the association of serum FSH and DHEA-S level with clinicopathological features of ovarian cancer. There was no significant association of serum FSH level with either histopathological type $(p=0.29)$, or grading $(p=0.23)$, or staging $(p=0.13)$ of ovarian cancer. While serum DHEA-S was found to be statically significant allied with well-differentiated ( $p=0.02$ ) ovarian tumor compared with moderately and poorly differentiated grade, and early FIGO staging $(p=0.001)$ compared with late FIGO staging of EOC. Median values of DHEA-S in early FIGO staging (stage I and II) were $154.7 \mathrm{ug} / \mathrm{dL}$ (range =99.4-258.9 ug/dL), while comparative value in late FIGO staging was $120.5 \mathrm{ug} / \mathrm{dL}$ (range $=85.4-199.7 \mathrm{ug} / \mathrm{dL}$ ) of EOC.

\section{Discussion}

Incessant ovulation and gonadotropin hypothesis are the two foremost elucidations for EOC etiology; however, limited experimental and epidemiologic evidence supports either of these. Moreover, research on prediagnosis endogenous androgens/gonadotropins concentration and EOC risk is scarce and has yielded inconclusive results. Therefore, this study considered it worthwhile to assess the prediagnostic serum levels of testosterone, DHEA-S, FSH, and LH with the EOC risk. We undeniably found a significant positive association of FSH and DHEA-S with the increased risk. These findings are in accord with some studies, ${ }^{22-25}$ but in contrast to others. ${ }^{26,27}$

In the primary analysis, prediagnostic levels of $\mathrm{FSH}$ $(p=0.02$; - Table 2$)$ and DHEA-S ( $p=0.03$; - Table 2) were elevated in EOC patients compared with healthy controls. Moreover, it was found that both elevated FSH and DHEA-S were associated with augmented risk for the occurrence of EOC after adjusting for various confounding factors and effective modifiers. However, this study failed to find any association of circulating blood level of $\mathrm{LH}$ and testosterone with the occurrence of EOC, while that was not the case in Ose et $\mathrm{al}^{27}$ and Keri et $\mathrm{al}^{28}$ but in agreement with Halperin et $\mathrm{al}^{29}$ and Tworoger et al. ${ }^{30}$

Among the study participants, the median level of FSH was $29.45 \%$ higher $(p=0.02)$ in cases $(58.9 \mathrm{IU} / \mathrm{L})$ than controls ( $45.5 \mathrm{IU} / \mathrm{L})$. The same is substantiated by a study ${ }^{22}$ reporting an increased gonadotropin level in the fluid of ovarian cancer, which might have originated from the high circulating level of gonadotropin. The association between serum FSH level 
52 Prediagnostic Circulating Levels of Gonadotropins and Androgens with Risk of EOC Parchwani et al.

Table 3 Association of serum FSH level with the occurrence of epithelial ovarian cancer

\begin{tabular}{|c|c|c|c|c|}
\hline FSH (IU/L) & $\begin{array}{l}\text { Low tertile } \\
<32.5\end{array}$ & $\begin{array}{l}\text { Mid tertile } \\
32.5-72.6\end{array}$ & $\begin{array}{l}\text { High tertile } \\
>72.6\end{array}$ & $p$ trend \\
\hline \multicolumn{5}{|l|}{ Parity of $0-2$} \\
\hline Case & 18 & 22 & 32 & \multirow[t]{3}{*}{0.03} \\
\hline Controls & 26 & 29 & 17 & \\
\hline OR $(95 \% \mathrm{Cl})$ & 1.0(ref.) & $1.1(0.48-2.48)$ & $2.7(1.17-6.30)$ & \\
\hline \multicolumn{5}{|c|}{ Menopause status } \\
\hline \multicolumn{5}{|c|}{ Premenopausal } \\
\hline Case & 12 & 13 & 17 & \multirow[t]{3}{*}{0.20} \\
\hline Controls & 19 & 14 & 11 & \\
\hline OR $(95 \% \mathrm{Cl})$ & 1.0 (ref.) & $1.4(0.51-4.18)$ & $2.4(0.85-6.97)$ & \\
\hline \multicolumn{5}{|c|}{ Postmenopausal } \\
\hline Case & 13 & 14 & 31 & \multirow[t]{3}{*}{0.04} \\
\hline Controls & 24 & 13 & 19 & \\
\hline OR $(95 \% \mathrm{Cl})$ & 1.0 (ref.) & $1.9(0.72-5.47)$ & $3.0(1.24-7.29)$ & \\
\hline \multicolumn{5}{|c|}{ Duration of menopause } \\
\hline \multicolumn{5}{|c|}{$\leq 10 \mathrm{y}$} \\
\hline Case & 09 & 07 & 18 & \multirow[t]{3}{*}{0.44} \\
\hline Controls & 13 & 08 & 13 & \\
\hline OR $(95 \% \mathrm{Cl})$ & 1.0 (ref.) & $1.2(0.33-4.74)$ & $2.0(0.65-6.06)$ & \\
\hline \multicolumn{5}{|l|}{$>10 y$} \\
\hline Case & 04 & 07 & 13 & \multirow[t]{3}{*}{0.04} \\
\hline Controls & 11 & 05 & 06 & \\
\hline OR $(95 \% \mathrm{Cl})$ & 1.0 (ref.) & $3.8(0.76-19.46)$ & $5.9(1.33-26.66)$ & \\
\hline \multicolumn{5}{|l|}{ Never used OCP } \\
\hline Case & 20 & 25 & 35 & \multirow[t]{3}{*}{0.03} \\
\hline Controls & 32 & 18 & 22 & \\
\hline OR $(95 \% \mathrm{Cl})$ & 1.0 (ref.) & $2.2(0.79-5.06)$ & $2.5(1.17-5.51)$ & \\
\hline \multicolumn{5}{|l|}{ Never used HRT } \\
\hline Case & 17 & 29 & 30 & \multirow[t]{3}{*}{0.01} \\
\hline Controls & 34 & 24 & 19 & \\
\hline OR $(95 \% \mathrm{Cl})$ & 1.0 (ref.) & $2.4(1.09-5.34)$ & $3.1(1.39-7.15)$ & \\
\hline \multicolumn{5}{|c|}{ Never used to smoke } \\
\hline Case & 17 & 33 & 39 & \multirow[t]{3}{*}{0.02} \\
\hline Controls & 38 & 37 & 23 & \\
\hline OR $(95 \% \mathrm{Cl})$ & 1.0 (ref.) & $1.9(0.95-4.10)$ & $3.7(1.7-8.18)$ & \\
\hline
\end{tabular}

Abbreviations: $\mathrm{Cl}$, confidence interval; FSH, follicle-stimulating hormone; HRT, hormone replacement therapy; OCP, oral contraceptive pill; OR, odds ratio.

Note: $\mathrm{OR}$ is calculated by conditional logistic regression.

expressed as tertiles and the risk of EOC reveals that high tertile level was significantly associated with increased risk of EOC in various subgroups, namely parity of 0 to 2 , menopausal duration greater than 10 years, smoking habit, and participants who never used OCP or HRT. The adjusted OR comparing the highest third tertile with the bottom third quartile was $2.7(95 \% \mathrm{CI}=1.17-6.3 ; p=0.03)$ for subgroup defined as parity of 0 to $2 ; 5.9(95 \% \mathrm{CI}=1.33-26.66 ; p=0.04)$ for menopausal duration greater than 10 years; $2.5(95 \% \mathrm{CI}=1.17-5.51$; $p=0.03$ ) for subgroup who never used OCP; 3.1 (95\% CI $=1.39-7.15 ; p=0.01$ ) for subgroup who were never on HRT; and 3.7 (95\% CI: 1.7-8.18; $p$ : 0.02 ) for subgroup who never used to smoke. This is in stark contrast to Arslan et $\mathrm{al}^{26}$ and McSorley et $\mathrm{al}^{31}$ wherein a high level of FSH have been reported to be a protective factor for ovarian cancer, but in concordance with the great majority of the researches $22,32-34$ 
Table 4 Association of serum DHEA-S level with the occurrence of epithelial ovarian cancer

\begin{tabular}{|c|c|c|c|c|}
\hline DHEA-S (ug/dL) & $\begin{array}{l}\text { Low tertile } \\
<106.9\end{array}$ & $\begin{array}{l}\text { Mid tertile } \\
106.9-194.2\end{array}$ & $\begin{array}{l}\text { High tertile } \\
>194.2\end{array}$ & $p$ trend \\
\hline \multicolumn{5}{|l|}{ Parity of $0-2$} \\
\hline Case & 13 & 24 & 35 & \multirow[t]{3}{*}{0.02} \\
\hline Controls & 22 & 30 & 20 & \\
\hline OR $(95 \% \mathrm{Cl})$ & 1.0 (ref.) & $1.3(0.56-3.23)$ & $2.9(1.23-7.13)$ & \\
\hline \multicolumn{5}{|c|}{ Menopause status } \\
\hline \multicolumn{5}{|l|}{ Premenopausal } \\
\hline Case & 7 & 10 & 25 & \multirow[t]{3}{*}{0.03} \\
\hline Controls & 15 & 15 & 14 & \\
\hline OR $(95 \% \mathrm{Cl})$ & 1.0 (ref.) & $1.4(0.42-4.75)$ & $3.8(1.26-11.61)$ & \\
\hline \multicolumn{5}{|c|}{ Postmenopausal } \\
\hline Case & 17 & 21 & 20 & \multirow[t]{3}{*}{0.52} \\
\hline Controls & 21 & 18 & 17 & \\
\hline OR $(95 \% \mathrm{Cl})$ & 1.0 (ref.) & $1.4(0.58-3.53)$ & $1.4(0.58-3.60)$ & \\
\hline \multicolumn{5}{|c|}{ Duration of menopause } \\
\hline \multicolumn{5}{|l|}{$\leq 10 \mathrm{y}$} \\
\hline Case & 10 & 14 & 10 & \multirow[t]{3}{*}{0.77} \\
\hline Controls & 12 & 11 & 11 & \\
\hline OR $(95 \% \mathrm{Cl})$ & 1.0 (ref.) & $1.5(0.48-4.83)$ & $1.1(0.32-3.61)$ & \\
\hline \multicolumn{5}{|l|}{$>10 y$} \\
\hline Case & 07 & 07 & 10 & \multirow[t]{3}{*}{0.55} \\
\hline Controls & 09 & 07 & 06 & \\
\hline OR $(95 \% \mathrm{Cl})$ & 1.0 (ref.) & $1.2(0.30-4.42)$ & $2.1(0.52-8.81)$ & \\
\hline \multicolumn{5}{|l|}{ Never used OCP } \\
\hline Case & 19 & 26 & 35 & \multirow[t]{3}{*}{0.01} \\
\hline Controls & 27 & 29 & 16 & \\
\hline OR $(95 \% \mathrm{Cl})$ & 1.0 (ref.) & $1.2(0.57-2.80)$ & $3.1(1.35-7.15)$ & \\
\hline \multicolumn{5}{|l|}{ Never used HRT } \\
\hline Case & 19 & 28 & 29 & \multirow[t]{3}{*}{0.02} \\
\hline Controls & 35 & 20 & 22 & \\
\hline OR $(95 \% \mathrm{Cl})$ & 1.0 (ref.) & $2.5(1.15-5.74)$ & $2.5(1.10-5.33)$ & \\
\hline \multicolumn{5}{|c|}{ Never used to smoke } \\
\hline Case & 23 & 29 & 37 & \multirow[t]{3}{*}{0.01} \\
\hline Controls & 41 & 23 & 24 & \\
\hline OR $(95 \% \mathrm{Cl})$ & 1.0 (ref.) & $2.2(1.06-4.75)$ & $2.7(1.33-5.67)$ & \\
\hline
\end{tabular}

Abbreviations: $\mathrm{Cl}$, confidence interval; DHEA-S, dehydroepiandrosterone-sulfate; HRT, hormone replacement therapy; OCP, oral contraceptive pill; OR, odds ratio.

Note: OR is calculated by conditional logistic regression.

and also in line with the gonadotropin hypothesis of ovarian carcinogenesis.

The pathophysiology behind the observed effect seems to be follicular development, resultant in the effect of FSH on theca and granulose cells. ${ }^{23}$ High gonadotropin entraps the ovarian epithelial cells in an inclusion cyst, and causes augmented estrogenic stimulation of ovarian epithelial cells, which is responsible for its increased proliferation and subse- quent malignant transformation. Excess gonadotropins are prime to the development of ovarian cancer as they have also been associated with surge during ovulation and deficient gonad negative feedback for premature ovarian failure and menopause. There is a suggestive inverse association between pregnancy and OCP with ovarian cancer risk by decreasing gonadotropins via steroidal feedback on the pituitary gland ${ }^{23,24}$; similar relationships persisted in the current study 
Table 5 Association of serum FSH and DHEA-S level with clinicopathological features

\begin{tabular}{|c|c|c|}
\hline & Serum FSH (IU/L) & Serum DHEA-S (ug/dL) \\
\hline \multicolumn{3}{|l|}{ Histopathology } \\
\hline Serous type & $48.9(16.3-98.7)$ & $153.9(96.7-258.9)$ \\
\hline Nonserous type & $51.2(8.3-106.7)$ & 150.7 (99.4-237.8) \\
\hline$p$-Value ${ }^{a}$ & 0.29 & 0.21 \\
\hline \multicolumn{3}{|l|}{ Grade } \\
\hline Well differentiated & $48.2(16.3-92.2)$ & $164.8(85.4-258.9)$ \\
\hline Moderately differentiated & $52.3(25.4-106.7)$ & $149.8(95.8-210.9)$ \\
\hline Poorly differentiated & $50.1(8.3-92.5)$ & 136.5 (99.4-196.7) \\
\hline$p$-Value ${ }^{\mathrm{b}}$ & 0.23 & 0.02 \\
\hline \multicolumn{3}{|l|}{ Staging } \\
\hline Early staging (I and II) & $51.2(18.3-92.7)$ & 154.7 (99.4-258.9) \\
\hline Late staging (III and IV) & $54.3(30.4-106.7)$ & $120.5(85.4-199.7)$ \\
\hline$p$-Value ${ }^{\mathrm{b}}$ & 0.13 & 0.001 \\
\hline
\end{tabular}

Abbreviations: DHEA-S, dehydroepiandrosterone-sulfate; FSH, follicle-stimulating hormone.

${ }^{a} p$-Values are calculated by Mann-Whitney $U$ test.

${ }^{b} p$-Values are calculated by Kruskal-Wallis test.

(-Table 3), further providing epidemiologic evidence in support of the gonadotropin hypothesis. With repute to circulating $\mathrm{LH}$, we have not found any evidence of an association between serum LH level and EOC, and neither we observed any protective effect of LH on ovarian cancer, as exemplified by Helzlsouer et al. ${ }^{35}$ This is in harmony with Halperin et al $^{29}$ and Akhmedkhanov et al. ${ }^{36}$ However, a handful of observations are also in conflict with the gonadotropin hypothesis, as illustrated by Ushiroyama et $\mathrm{al}^{37}$ that estrogen replacement therapy, which reduces circulating gonadotropins and, thus, should confer protection, appears to be associated with a moderately increased risk of ovarian cancer. ${ }^{38}$

We did not observe any statistically significant association with testosterone and risk of EOC in premenopausal or postmenopausal women or overall, similar to that of Rinaldi et $\mathrm{al}^{9}$ and Lukanova et al. $^{25}$ Among the study participants, the median level of DHEA-S was $14.92 \%$ higher $(p=0.03)$ among cases (163.43 ug/dL) than among controls (142.2 ug/dL). The association between serum DHEA-S levels expressed as tertiles and the risk of EOC reveals that a high tertile level of DHEA-S was significantly associated with increased risk of EOC in premenopausal women. Compared with women categorized in the lowest third of DHEA-S concentrations in the premenopause subgroup, the OR increased to 1.4 $(95 \% \mathrm{CI}=0.42-4.75)$ and $3.8(95 \% \mathrm{CI}=1.26-11.61)$ in the middle and highest thirds, respectively. Comparable results were obtained through conditional logistic regression analysis in other subclassified groups (namely parity of $0-2$, never used to smoke, and participants who never used OCP and HRT), also there was a progressive increase in OR from the middle to highest third tertile group of DHEA-S compared with the lowest third (-Table 4). Our observed associations also seem consistent with Helzlsouer et al. ${ }^{35}$

DHEA-S is a major circulatory androgen in women derived from the adrenal glands. Animal model studies have provid- ed strong evidence that ovarian cancer preferentially progresses in a hormonal milieu enriched with androgens by accelerating proliferation of epithelial cells of the ovary directly through androgen receptor signaling ${ }^{6}$ and reduced apoptotic rates or through their role as estrogen precursors. ${ }^{39}$ Androgens have also been associated with the increased invasive potential of ovarian epithelial cells by stimulating matrix metalloproteinases. ${ }^{40}$ Taken together, androgens (directly or after conversion to estrogens) may contribute to growth promotion and/or differentiation in the early stages of the disease. On evaluating the association between studied parameters and clinicopathological features of the disease (histopathological type, grading, and staging), it was found that DHEA-S level was significantly high in well-differentiated tumor and early stage of ovarian cancer; this pattern exhibited by DHEA-S with ovarian cancer risk is unique and is challenging to explain the underlying pathophysiology. While serum FSH did not unveil any association with either histopathological type $(p=0.29)$, or grading $(p=0.23)$, or staging $(p=0.13)$ of ovarian malignancy.

To the best of our knowledge, based on the PubMed database, this is the first study in the North Indian population to detect the role of gonadotropins and androgens in the development of ovarian cancer. Other potential strengths of the study include the selection criteria of the patient cohort as patients with features suggestive of any other malignancy or benign ovarian tumors were excluded, thus confined the study to EOC; we designed and performed this study in a manner where we adjusted several confounding variables and effective modifiers, thus rule out or at least minimizes the possibility of any biases that may lead to potential false-positive or falsenegative results. Finally, prediagnostic samples were used for the biochemical variable analysis, thus minimizing the possibility of the disease's effect on the circulating hormones. Nonetheless, our findings described here are only statistical 
observations, provide only the association's evidence, and cannot provide a causal relationship. Other limitations include that this study was performed in a relatively small population from one hospital, which may not represent the entire patient population. The generalizability of these findings will need to be confirmed in future multicentric prospective design studies after incorporating larger groups with the inclusion of other hormones like estrogen, progesterone, and sex hormone binding globulin. Despite these limitations, we believe that the findings of this study can be helpful for outcome predictions, and variables pointed here should be added to the screening profile of EOC. However, alliance or enmity in some subgroups/variables warrants additional evaluation.

\section{Conclusion}

To summarize and conclude, our study reveals a statistically significant elevated prediagnostic circulating concentration of serum FSH and DHEA-S in EOC patients compared with healthy controls. Furthermore, these abnormalities were significantly associated with increased occurrence of EOC, in particular, elevated FSH in postmenopausal and DHEA-S in premenopausal women. Thus, this study, in unification with prevailing prospective epidemiological studies, supports the hypothesis that circulating FSH and DHEA-S concentrations is a putative risk factor for ovarian cancer. This emphasizes the need to add these variables in the screening profile of EOC for early recognition and scheduling necessary interventions/management strategies.

Funding

We did not receive any funding for this research work.

\section{Conflict of Interest}

The author(s) declared no conflicts of interest.

Acknowledgment

None.

\section{References}

1 Siegel RL, Miller KD, Jemal A. Cancer statistics, 2019. CA Cancer J Clin 2019;69(01):7-34

2 Takiar R. Status of ovarian cancer in India. EC Gynaecol 2019;8 (05):358-364

3 Maheshwari A, Kumar N, Mahantshetty U. Gynecological cancers: a summary of published Indian data. South Asian J Cancer 2016;5 (03):112-120

4 Lynch HT, Casey MJ, Snyder CL, et al. Hereditary ovarian carcinoma: heterogeneity, molecular genetics, pathology, and management. Mol Oncol 2009;3(02):97-137

5 Zhu H, Zhu X, Zheng L, Hu X, Sun L, Zhu X. The role of the androgen receptor in ovarian cancer carcinogenesis and its clinical implications. Oncotarget 2017;8(17):29395-29405

6 Mizushima T, Miyamoto $\mathrm{H}$. The role of androgen receptor signaling in ovarian cancer. Cells 2019;8(02):176

7 Li S, Jiang K, Li J, et al. Estrogen enhances the proliferation and migration of ovarian cancer cells by activating transient receptor potential channel C3. J Ovarian Res 2020;13(01):20

8 Modugno F, Laskey R, Smith AL, Andersen CL, Haluska P, Oesterreich $\mathrm{S}$. Hormone response in ovarian cancer: time to reconsider as a clinical target? Endocr Relat Cancer 2012;19(06):R255-R279
9 Rinaldi S, Dossus L, Lukanova A, et al. Endogenous androgens and risk of epithelial ovarian cancer: results from the European Prospective Investigation into Cancer and Nutrition (EPIC). Cancer Epidemiol Biomarkers Prev 2007;16(01):23-29

10 Lonard DM, O'Malley BW. Nuclear receptor coregulators: modulators of pathology and therapeutic targets. Nat Rev Endocrinol 2012;8(10):598-604

11 Peres LC, Moorman PG, Alberg AJ, et al. Lifetime number of ovulatory cycles and epithelial ovarian cancer risk in African American women. Cancer Causes Control 2017;28(05):405-414

12 Momenimovahed Z, Tiznobaik A, Taheri S, Salehiniya H. Ovarian cancer in the world: epidemiology and risk factors. Int J Womens Health 2019;11(11):287-299

13 Daniilidis A, Dinas K. Long term health consequences of polycystic ovarian syndrome: a review analysis. Hippokratia 2009;13(02): 90-92

14 Ose J, Poole EM, Schock H, et al. Androgens are differentially associated with ovarian cancer subtypes in the ovarian cancer cohort consortium. Cancer Res 2017;77(14):3951-3960

15 Olsen CM, Green AC, Nagle CM, et al; Australian Cancer Study Group (Ovarian Cancer) and the Australian Ovarian Cancer Study Group. Epithelial ovarian cancer: testing the 'androgens hypothesis'. Endocr Relat Cancer 2008;15(04):1061-1068

16 Li AJ, Karlan BY. Androgens and epithelial ovarian cancer: what's the connection? Cancer Biol Ther 2008;7(11):1712-1716

17 Gründker C, Emons G. Role of gonadotropin-releasing hormone $(\mathrm{GnRH})$ in ovarian cancer. Cells 2021;10(02):437

18 Zheng H, Kavanagh JJ, Hu W, Liao Q, Fu S. Hormonal therapy in ovarian cancer. Int J Gynecol Cancer 2007;17(02):325-338

19 Williams C, Simera I, Bryant A. Tamoxifen for relapse of ovarian cancer. Cochrane Database Syst Rev 2010;2010(03):CD001034

20 Desai A, Xu J, Aysola K, et al. Epithelial ovarian cancer: an overview. World J Transl Med 2014;3(01):1-8

21 Meeta DL, Digumarti L, Agarwal N, Vaze N, Shah R, Malik S. Clinical practice guidelines on menopause: an executive summary and recommendations. J Midlife Health 2013;4(02):77-106

22 Rzepka-Górska I, Chudecka-Głaz A, Kosmowska B. FSH and LH serum/tumor fluid ratios and malignant tumors of the ovary. Endocr Relat Cancer 2004;11(02):315-321

23 Choi JH, Wong AS, Huang HF, Leung PC. Gonadotropins and ovarian cancer. Endocr Rev 2007;28(04):440-461

24 Vanderhyden BC. Loss of ovarian function and the risk of ovarian cancer. Cell Tissue Res 2005;322(01):117-124

25 Lukanova A, Lundin E, Akhmedkhanov A, et al. Circulating levels of sex steroid hormones and risk of ovarian cancer. Int J Cancer 2003; 104(05):636-642

26 Arslan AA, Zeleniuch-Jacquotte A, Lundin E, et al. Serum folliclestimulating hormone and risk of epithelial ovarian cancer in postmenopausal women. Cancer Epidemiol Biomarkers Prev 2003;12(12):1531-1535

27 Ose J, Poole EM, Schock H, et al; Androgens Are Differentially Associated with Ovarian Cancer Subtypes in the Ovarian Cancer Cohort Consortium. Androgens are differentially associated with ovarian cancer subtypes in the ovarian cancer cohort consortium. Cancer Res 2017;77(14):3951-3960

28 Keri RA, Lozada KL, Abdul-Karim FW, Nadeau JH, Nilson JH. Luteinizing hormone induction of ovarian tumors: oligogenic differences between mouse strains dictates tumor disposition. Proc Natl Acad Sci U S A 2000;97(01):383-387

29 Halperin R, Pansky M, Vaknin Z, Zehavi S, Bukovsky I, Schneider DSackler Faculty of Medicine, Tel Aviv University, Israel. Luteinizing hormone in peritoneal and ovarian cyst fluids: a predictor of ovarian carcinoma. Eur J Obstet Gynecol Reprod Biol 2003;110 (02):207-210

30 Tworoger SS, Lee IM, Buring JE, Hankinson SE. Plasma androgen concentrations and risk of incident ovarian cancer. Am J Epidemiol 2008;167(02):211-218 
31 McSorley MA, Alberg AJ, Allen DS, et al. Prediagnostic circulating follicle stimulating hormone concentrations and ovarian cancer risk. Int J Cancer 2009;125(03):674-679

32 Chen FC, Oskay-Ozcelik G, Bühling KJ, et al. Prognostic value of serum and ascites levels of estradiol, FSH, LH and prolactin in ovarian cancer. Anticancer Res 2009;29(05):1575-1578

33 Irvin SR, Weiderpass E, Stanczyk FZ, et al. Association of antiMullerian hormone, follicle-stimulating hormone, and inhibin B with risk of ovarian cancer in the Janus Serum Bank. Cancer Epidemiol Biomarkers Prev 2020;29(03):636-642

34 Chudecka-Głaz A, Rzepka-Górska I, Kosmowska B. Gonadotropin ( $\mathrm{LH}, \mathrm{FSH}$ ) levels in serum and cyst fluid in epithelial tumors of the ovary. Arch Gynecol Obstet 2004;270(03):151-156

35 Helzlsouer KJ, Alberg AJ, Gordon GB, et al. Serum gonadotropins and steroid hormones and the development of ovarian cancer. JAMA 1995;274(24):1926-1930

36 Akhmedkhanov A, Toniolo P, Zeleniuch-Jacquotte A, Pettersson KS, Huhtaniemi IT. Luteinizing hormone, its beta-subunit variant, and epithelial ovarian cancer: the gonadotropin hypothesis revisited. Am J Epidemiol 2001;154(01):43-49

37 Ushiroyama T, Sakai M, Higashiyama T, Ikeda A, Ueki M. Estrogen replacement therapy in postmenopausal women: a study of the efficacy of estriol and changes in plasma gonadotropin levels. Gynecol Endocrinol 2001;15(01):74-80

38 Lee AW, Ness RB, Roman LD, et al; Ovarian Cancer Association Consortium. Association between menopausal estrogen-only therapy and ovarian carcinoma risk. Obstet Gynecol 2016;127 (05):828-836

39 Ciucci A, Zannoni GF, Buttarelli M, et al. Multiple direct and indirect mechanisms drive estrogen-induced tumor growth in high grade serous ovarian cancers. Oncotarget 2016;7(07): 8155-8171

40 Sood AK, Bhatty R, Kamat AA, et al. Stress hormone-mediated invasion of ovarian cancer cells. Clin Cancer Res 2006;12(02): 369-375 